\title{
O ENSINO DE LÍNGUA INGLESA NA CONTEMPORANEIDADE: ANÁLISE DE UNIDADES DE LIVROS DIDÁTICOS DE ALCANCE GLOBAL DE ACORDO COM O PARADIGMA DO INGLÊS COMO LÍNGUA INTERNACIONAL (ILI)
}

\author{
Caio Antônio Nóbrega \\ Doutorando em Letras pela Universidade Federal da Paraíba [Bolsista CNPq] \\ caioamnobrega@gmail.com
}

\section{RESUMO}

Neste artigo, objetivamos analisar duas unidades de dois livros didáticos de ensino de inglês que possuem alcance global, a partir dos preceitos que fundamentam a área de Inglês como língua internacional (ILI). Para tanto, fazemos um percurso teórico em que discutimos algumas das principais questões que envolvem a área de ILI, sua intersecção potencialmente descolonizadora com a Linguística Aplicada, bem como tratamos da relação entre livros didáticos e ensino de ILI. A análise demonstra que os dois livros cotejados não se encontram plenamente articulados aos preceitos pedagógicos de ILI; de fato, algum grau de adaptação ou complementação é necessário. Nosso referencial teórico-metodológico é composto especialmente de estudos feitos por linguistas que se debruçam sobre ILI, seus preceitos pedagógicos e seu potencial descolonizador, a exemplo de Kumaravadivelu (2012), Matsuda (2012), Ilieva (2018), entre outros.

Palavras-chave: linguística aplicada; ensino de inglês; inglês como língua internacional; livro didático.

\section{ABSTRACT}

In this paper, we aim at analyzing two units from two globally distributed English textbooks according to the paradigm of English as an international language (EIL). We present some of the main issues regarding the field of EIL, the potentially decolonial intersection between EIL and Applied Linguistics, and discuss the status of textbooks in EIL. The analysis indicates that both textbooks are not completely articulated with the fundaments of EIL; there needs to exist some degree of adaptation or complementation. Our theoretical framework is composed mainly by studies elaborated by applied linguists on the subjects of EIL, its pedagogical implications and decolonial potential, such as Kumaravadivelu (2012), Matsuda (2012), Ilieva (2018), among others.

Keyworks: applied linguistics; English language teaching; English as an international language; textbook. 


\section{Introdução}

Na contemporaneidade, o movimento de globalização diminuiu significativamente as distâncias espaço-temporais através de um grande avanço pelo qual passaram as tecnologias de transporte e de informação. A comunicação internacional, especialmente, seja presencialmente ou de modo virtual, através da internet, está cada vez mais presente na vida das pessoas, empresas e instituições. Nesse panorama, a língua inglesa vem continuamente ganhando mais importância e destaque no cenário internacional, como um meio que possibilita o diálogo entre indivíduos que não compartilham uma mesma língua materna.

Em meio a esse ambiente de expansão da língua inglesa, diversos estudiosos (McKAY, 2012; KUMARAVADIVELU, 2012) têm refletido sobre o alcance do idioma enquanto uma língua para a comunicação internacional - ou, mais simplesmente, inglês como língua internacional (daqui em diante, ILI). Diversos marcos teóricos e metodológicos caracterizam as discussões da área, bem como a prática pedagógica que dela se depreende: em geral, tais marcos afirmam a não primazia de uma variante da língua sobre outra menos prestigiada (a exemplo da variante estadunidense em relação à sul-africana), defendendo, acima de tudo, o respeito pela diferença, pelas diversas formas de falar e pelos diversos falantes.

No processo de desenvolvimento dessa consciência nos alunos e em professores imersos em aulas de ILI, os livros didáticos podem vir a desempenhar um papel fundamental ao representarem a diversidade de usos, usuários e variantes de inglês que existem no mundo. De fato, é mesmo argumentado (ILIEVA, 2018; MATSUDA, 2012) que os livros didáticos podem ter uma importância maior dentro da área de ILI que em outras 
áreas correlatas, como inglês como segunda língua ou como língua estrangeira. Isso justifica, portanto, a análise de possíveis materiais já disponíveis e sua possível adequação para aulas de ILI.

É nesse sentido que, neste artigo, objetivamos analisar duas unidades sobre casas e moradias de dois livros didáticos de ensino de inglês que possuem alcance global, a partir dos preceitos que fundamentam a área de ILI. Os livros são English File: Elementary (2015) e World English - Intro (2010), publicados, respectivamente, pelas grandes editoras Oxford University Press e Cengage Learning. Para tanto, em um primeiro momento, discutiremos algumas questões referentes ao ILI e à Linguística Aplicada (daqui em diante, LA), especialmente no que concerne o potencial descolonizador que ambos possuem. A seguir, apresentaremos algumas das principais noções que circunscrevem os livros didáticos em meio às discussões da área de ILI. Por fim, analisamos unidades dos dois livros referidos a partir dos fundamentos do campo de estudo de ILI.

\section{Inglês como língua internacional}

De acordo com Kumaravadivelu (2012), ao refletirmos sobre a substancial difusão da língua inglesa na contemporaneidade, devemos considerar, em conjunto, seu alcance global e sua história de dominação colonial. De fato, uma análise crítica sobre o estágio atual da língua inglesa não pode prescindir de uma avaliação sobre as práticas coloniais do antigo Império Britânico e de um exame sobre as atuais políticas (neo-)imperialistas das grandes potências mundiais que têm inglês como língua materna, especialmente os Estados Unidos e o Reino Unido. A história de colonização e de imperialismo espaciais, 
econômicos, culturais etc, tem reflexos claros sobre as políticas educacionais de ensino de inglês como língua estrangeira ou como segunda língua.

Como uma tentativa de refletir sobre e combater os reflexos do passado e do presente de dominação anglófona, estudiosos e linguistas aplicados têm se engajado nas discussões de um novo paradigma para o ensino dessa língua, um paradigma que percebe o ILI. Através dessa percepção, entende-se que esse idioma não tem dono - dessa forma, os estadunidenses ou ingleses não podem ter a prerrogativa de quererem influenciar qual inglês deve ser valorizado, ensinado, falado (KACHRU, 2005). Além da propriedade, vários outros assuntos têm sido problematizados dentro do campo do ILI, como "a estigmatização de falantes não nativos, questões de identidade linguística [...], respeito por diferentes culturas e preocupações relativas ao inglês como meio de comunicação intercultural entre falantes não nativos de língua inglesa" ${ }^{1}$ (SHIN; ESLAMI; CHEN, 2011, p. 254).

De acordo com McKay (2012), as discussões sobre ILI surgiram nas últimas décadas, em meio à percepção de que há mais falantes de inglês como segunda língua (habitantes das antigas colônias inglesas, como Hong Kong e Nigéria, por exemplo) e como língua estrangeira (a exemplo dos latino-americanos) do que propriamente falantes nativos do idioma. Além disso, em boa parte das comunicações por meio do inglês, entre pessoas que não compartilham uma mesma língua materna, não há nenhum falante nativo dessa língua envolvido. Como consequência, o campo de ILI foi instituído através de uma aceitação das normas e valores linguísticos de todos os falantes do idioma e de uma compreensão do inglês como uma língua franca, como um meio de comunicação intercultural (SHIN; ESLAMI; CHEN, 2011). 
McKay (2012) apresenta diversos princípios que guiam o ensino de ILI. Entre eles, destacam-se especialmente: 1 . o respeito por e a promoção do multilingualismo; 2 . uma pedagogia que dialogue com a paisagem linguística local; 3. cursos de conscientização linguística para todos os alunos, que possam contribuir para uma consciência crítica acerca da língua; 4. um exame dos discursos que promovem o aprendizado do inglês; e 5. currículos que promovam conscientização intercultural. Em linhas gerais, McKay delineia o que ela considera os princípios que podem fundar uma pedagogia de ensino de ILI que seja sensível às questões sociais. Ou, como afirma Matsuda (2012, p. 170), "em aulas de ILI, um dos mais importantes objetivos é desenvolver uma consciência e uma sensibilidade voltadas para as diferenças - diferenças em formas, usos e usuários - e aprender a respeitar (ou ao menos tolerar) tais diferenças".

As discussões sobre ILI encontraram terreno especialmente fértil para florescer em meio à área de Linguística Aplicada. Uma vez que, na área de LA, há uma preocupação especial em relação às situações e aos contextos em que a linguagem tem implicações em ambientes educacionais, tais questões que marcam a experiência contemporânea são contempladas através de teorizações e de propostas pedagógicas. Nesse sentido, podemos perceber claras ligações entre o ensino de ILI e as discussões que giram em torno dos multiletramentos, especialmente em sua defesa da promoção e do respeito pela diversidade linguística e cultural.

De acordo com Roxane Rojo (2012), na contemporaneidade, vivemos em sociedades híbridas, impuras, fronteiriças. Isso significa que não é mais possível pensar em uma cultura única e/ou unificada. Não mais deveria se sustentar, portanto, o ensino exclusivo de variantes britânicas e/ou estadunidenses de língua inglesa: essa forma tradicional de pensar e ensinar o idioma não se reflete na maior parte das comunicações 
a nível internacional com as quais irá se deparar o aprendiz de inglês. Em aulas de ILI, dessa forma, é necessário que haja o desenvolvimento da consciência de que as diversas variantes do inglês devem ser respeitadas, pois refletem vivências sócio-histórica específicas e até mesmo escolhas pessoais, que não podem ser ignoradas nem tampouco tratadas como inferiores.

Por fim, convém ressaltar que ambos o ILI e a LA, em possível intersecção no Brasil, trazem consigo o potencial de promover uma revisão crítica em relação ao ensino de língua inglesa. Estamos nos referindo, mais especificamente, à proposta descolonizadora que compartilham o ILI, em contexto global, e a LA, em contexto nacional - ver, nesse sentido, as discussões de teóricos como Moita Lopes (2006) e Kleiman (2013). Nas atividades de ensino e de pesquisa em torno da língua inglesa através do paradigma do ILI, isso pode significar uma indisciplina em relação aos preceitos teórico-metodológicos que prevalecem em contextos europeus e norte-americanos.

No Brasil, a área de LA se engaja com pesquisas e ações interventivas que trazem em si um potencial de mudança social, com o objetivo de criar alternativas especialmente voltadas para e a partir da voz daqueles grupos que estão às margens, a fim de levar adiante um projeto de pesquisa e de ação/intervenção, o que pode vir a dialogar proximamente com os preceitos traçados no campo de ILI. Através da intersecção dessas duas áreas interdisciplinares, linguistas e professores brasileiros podem vir a perseguir uma trilha descolonial, através da percepção de que as respostas para os problemas do Sul estão no próprio Sul, a partir das vozes e dos conhecimentos aqui produzidos. Isso significa não consumir acriticamente os discursos e saberes produzidos pelo Norte (aqui representado especialmente pelos Estados Unidos e pela Europa Ocidental), buscando, por outro lado, um “'suleamento' [...] de nossa atividade acadêmica, por meio do 
estabelecimento de mais diálogos com outros cientistas sociais críticos 'de fronteira'” (KLEIMAN, 2013, p. 41), no desenvolvimento de um "diálogo intercultural Sul-Sul" (DUSELL apud KLEIMAN, 2013, p. 41).

\section{Inglês como língua internacional e livros didáticos}

Em meio às reflexões e problematizações desenvolvidas na área de ILI, um dos tópicos que tem recebido maior destaque é aquele sobre livros didáticos. De acordo com Kumaravadivelu (2012), livros didáticos constituem a forma mais visível da dominação e do colonialismo ainda existentes por parte de países como os Estados Unidos e o Reino Unido sobre a indústria editorial de materiais didáticos. Para o linguista, isso tem implicações diretas no ensino e na aprendizagem de língua inglesa, posto que os livros didáticos podem atuar fortemente na propagação de um determinado método de ensino, cunhado por e desenvolvido muitas vezes pensando-se em públicos ocidentais. Para além desse fato, convém ressaltar que livros didáticos também têm influência direta em relação à(s) variante(s) de inglês que são ensinadas, bem como na representação das identidades de falantes e aprendizes que são articuladas e propagadas pelo material.

Questões culturais e como são representadas em livros didáticos também têm recebido atenção por parte de estudiosos da área de ILI. De acordo com llieva (2018, p. 5), na área de ILI, a intersecção entre livros didáticos e ensino de inglês possibilita a percepção de que "o currículo não é neutro e que livros didáticos são o artefato curricular que tem uma importância substancial na definição de que cultura e conhecimentos são ensinados". A estudiosa referencia diversas pesquisas já realizadas que reportam a existência de uma desigualdade entre as representações articuladas pelos livros didáticos, 
representações essas que se tornam disponíveis para o consumo de professores e alunos e que são capazes de influenciá-los.

De fato, há uma concordância entre estudiosos de livros didáticos dentro da área de ILI de que materiais didáticos, especialmente aqueles criados para serem distribuídos em escala global, costumam se articular muito proximamente à forma de vida e ideologia ocidentais. Para além disso, tais materiais privilegiam sobremaneira variantes, usos e usuários provenientes dos Estados Unidos e do Reino Unido - países de onde vêm, não coincidentemente, as maiores casas editoriais que publicam materiais didáticos para ensino de inglês. Ainda, tais livros didáticos, de acordo com Matsuda (2012, p. 171), promovem a ideia de que o objetivo para se aprender o idioma é a interação com falantes nativos de inglês, falantes esses que são associados àqueles provenientes, mais uma vez, dos Estados Unidos e do Reino Unido. Como já apontado, tal panorama simplesmente não coincide com a realidade dos diversos usos que compõem o campo do ILI.

A discussão sobre livros didáticos, relacionada aos preceitos do ILI, faz-se necessária pois tais materiais são "influentes portadores de culturas e fornecedores de um ponto 'focal' a partir de onde professores e alunos negociam formas particulares de existência, sistemas de valores e usos linguísticos neles representados" (ILIEVA, 2018, p. 5). Dessa maneira, livros didáticos acabam por legitimar e propagar certas maneiras de pensar e de existir em detrimento de outras. Considerando a história de colonialismo que marca a expansão e a manutenção da primazia da língua inglesa, llieva (2018) chama ainda atenção para o fato de que livros didáticos distribuídos em escala global são especialmente ideológicos pois costumam reproduzir discursos que procuram manter o status quo, em termos de classe, raça, gênero, etc. Além disso, a estudiosa ainda aponta que eles podem promover imperialismo linguístico, devido a seu conteúdo 
exclusivamente em inglês e à promoção incessante da ideia corrosiva de um falante nativo idealizado, que serve como objetivo, ponto de chegada para os aprendizes.

Dessa forma, uma vez que as práticas de discursivas criam sentidos que incidem diretamente sobre formações identitárias, é muito importante que se tenha cuidado na escolha do material didático e das discussões a serem realizadas em sala de aula. Andrade (2014), embora não no contexto de ILI, argumenta, nesse sentido, que na seleção de textos, a escolha deve ser pautada por uma variação não somente de usos da linguagem e de gêneros textuais, mas também de representações de sujeitos e de identidade diversas. Para a linguista,

\begin{abstract}
quando o livro didático ignora o poder da linguagem como multiplicador e reprodutor de valores culturais e de representações socialmente compartilhadas, ignora igualmente seu poder - que é legitimado pelos órgãos oficiais que o avaliaram e o recomendaram - não só de reforçar estereótipos, mas também de tornar invisíveis outras formações discursivas que não são hegemônicas e, por isso, silenciadas (ANDRADE, 2014, p. 159-160).
\end{abstract}

No contexto de publicações de alcance global de livros didáticos para o ensino de língua inglesa, é preocupante o fato de que tais materiais costumeiramente apresentamse como "higienizados", não trazendo em si diversas percepções plurais sobre os temas representados (ILIEVA, 2018). Tal visão limitada pode ser bastante prejudicial para os alunos: se, por um lado, tal insuficiência pode vir a influenciar negativamente a visão dos alunos sobre variantes do inglês que não possuem o prestígio daquelas estadunidenses ou britânicas (MATSUDA, 2012), por outro, pode mesmo a vir prejudicar a aquisição da língua, quando não há semelhança alguma (ou pouquíssima semelhança) entre a visão de mundo representada e aquela do alunado (SHIN; ESLAMI; CHEN, 2011). 
Diversas recomendações têm sido feitas em relação ao uso de livros didáticos no âmbito do ensino de ILI. Ilieva (2018), nesse sentido, afirma que os diversos falantes de inglês devem estar representados nos livros didáticos - sejam falantes nativos, sejam falantes de inglês como segunda língua ou como língua estrangeira. Além disso, a estudiosa ainda aponta como relevante o fato de que devem ser representados, nos materiais, falantes de inglês que sejam semelhantes aos alunos que compõem o público alvo, uma vez que isso pode "fomentar um sentimento de domínio sobre o inglês nesses estudantes" (ILIEVA, 2018, p. 10). Matsuda (2012), por sua vez, em relação às representações culturais presentes nos livros didáticos, argumenta que elas devem ocorrer tendo em vista três diferentes dimensões: 1. a da cultura global (com temas como aquecimento global, preservação da natureza etc); 2 . a das diversas culturas dos falantes de língua inglesa (sejam nativos ou não); e 3. a cultura do próprio estudante.

Para finalizar essa seção, convém ressaltar que a existência de materiais adequados que se articulem aos preceitos do ensino de ILI pode ter importância ainda mais crítica para esse paradigma de ensino, quando comparado, por exemplo, ao ensino de inglês como segunda língua ou língua estrangeira. Isso se justifica pelo fato de que

[u]m objetivo do ensino de ILI é preparar os alunos para usar inglês a fim de se tornarem parte do mundo globalizado, linguística e culturalmente diversificado, e assim os cursos ILI naturalmente se esforçam para incorporar tal diversidade e representar o inglês como uma entidade pluralista e dinâmica, ao invés de monolítica e estática. Poucos professores, porém, têm conhecimento e experiência pessoal suficientes com todas as variantes e funções dos 'ingleses' que existem hoje e, portanto, precisam contar com materiais de ensino para apresentar aos alunos a diversidade linguística e cultural do inglês. Em outras palavras, os cursos e professores da EIL dependem de materiais didáticos bem elaborados que incluam amplas amostras linguísticas de 'ingleses' do mundo, bem como discussões metalinguísticas e representações abrangentes da disseminação global do inglês (MATSUDA, 2012, p. 169). 
E é com esse entendimento sobre a substancial relevância que têm os livros didáticos no processo de ensino e de aprendizagem de ILI que passamos à análise de duas unidades de materiais educativos, produzidos por grandes editoras, com alcance global, de acordo com os preceitos que formam o paradigma do ILI.

\section{Análise}

\subsection{Metodologia}

Dois livros didáticos de circulação global foram selecionados para análise de acordo com os preceitos que fundamentam o paradigma do ILI: os livros dos alunos [students' books] English File - Elementary (2015) e World English - Intro (2010). Esses livros foram respectivamente publicados pela Oxford University Press, com sede em Oxford, no Reino Unido, e pela Cengage Learning em parceria com a National Geographic, com sede em Mason, Ohio, Estados Unidos. O fato de que foram publicados nessa década, em um intervalo de cinco anos, também é um fator que contribuiu para a escolha, uma vez que já em 2010 havia um conjunto de textos teóricos sobre o ILI, o que teria permitido a autores e editores uma escolha por filiação ou não a tal paradigma. Além disso, convém ressaltar que ambos os livros são direcionados a um mesmo nível de proficiência: A1, de acordo com o Quadro Comum de Referência Europeu.

Escolhemos uma unidade em cada um desses livros a fim de proceder com a análise. No English File, a unidade selecionada foi a 8B, "A house with a history"; no World English, a unidade 3, "Houses and apartments". Ambas se desenvolvem ao redor 
de um mesmo tema: casas - ou moradias, de forma mais geral. Justifica-se trabalhar com unidades cujo tema é casas e/ou moradias pela possibilidade da realização de uma análise de questões culturais, identitárias e ideológicas, além, claro, daquilo que se refere às variantes linguísticas representadas.

Algumas questões guiarão a análise das unidades, de acordo com os fundamentos do paradigma de ILI. São elas:

- Quais variantes de inglês estão presentes nas unidades?

- O material procura desenvolver uma conscientização em relação à diversidade linguística que caracteriza o inglês na contemporaneidade?

- Quais culturas são representadas? (Ou, ainda melhor: A cultura de quem é representada?)

- Qual(is) cultura(s) ou forma(s) de ver o mundo predomina(m)?

- Em relação a um aluno brasileiro, pode-se afirmar que sua cultura foi contemplada? É possível que esse aluno explore e (re)negocie sua identidade a partir do material?

\subsection{English File}

A unidade do English File gira em torno da narrativa de um casal estadunidense que está procurando uma casa para alugar na Inglaterra, nos arredores de Oxford. As variantes orais estadunidense e britânica são aquelas trabalhadas na unidade, através de áudios e atividades de listening. Em relação à escrita, a variante britânica caracteriza a grafia dos textos, instruções e atividades. Não há, ao menos nessa unidade do livro, qualquer menção a alguma outra variante de inglês existente no mundo. Além disso, a 
cultura representada é tão somente e claramente aquela ocidental, proveniente de países anglófonos ricos, Estados Unidos e Inglaterra. Observemos, nesse sentido, a Figura 1:

Figura 1: Atividade de leitura e de vocabulário.

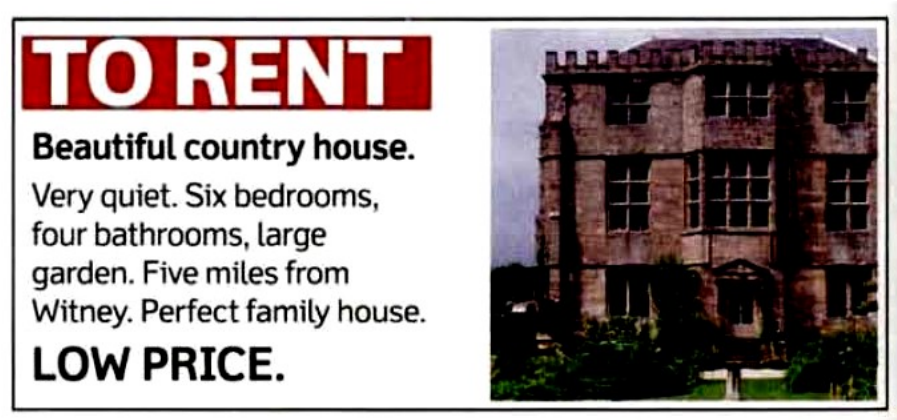

Fonte: LATHAM-KOENIG; OXENDEN; SELIGSON, 2015, p. 62.

A imagem, o anúncio e a descrição (especialmente a escolha dos adjetivos) fazem referência à cultura inglesa de ricas e imponentes casas de campo. Tais casas, que estão plenamente representadas na literatura e nas mídias audiovisuais inglesas, são conectadas a uma tradição de riqueza e prestígio britânicos - discurso que é confirmado pelo personagem estadunidense no áudio, quando afirma, apontando como ponto positivo, na tentativa de convencer sua esposa a alugar a casa, que aquela "é uma autêntica casa de campo inglesa". A noção de autenticidade, que ganha contornos bastante positivos na unidade e que é apontada como característica da casa e de uma tradição britânica, acaba por se estender também em direção às próprias cultura e variante de inglês britânico que são representadas e que predominam nos textos e exercícios.

Uma atividade de conversação nessa mesma unidade, representada na Figura 2, também é bastante significativa quando pensamos nas culturas e identidades representadas. 
Figura 2: Entrevista em pares

a Look at the questionnaire Your home. Interview a partner. Ask for and give more information if you can.

Your home H田田田

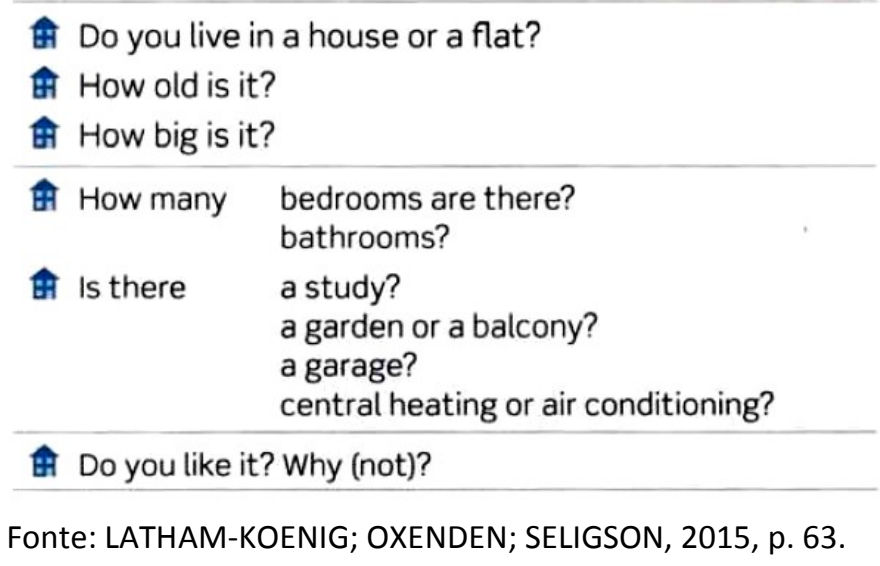

Essa atividade, para ser feita em pares, está diretamente ligada a um exercício anterior, que se encontra no banco de vocabulários do livro. Na primeira, há uma apresentação dos vários cômodos que são apontados como componentes de uma casa. $\mathrm{Na}$ atividade de conversação propriamente dita, tais cômodos devem ser recuperados durante a entrevista proposta. Esses são alguns dos cômodos que são referenciados na unidade: banheiro, quarto, sala de jantar, garagem, jardim, vestíbulo de entrada, cozinha, escritório e sala de estar. Além disso, móveis e eletrodomésticos também compõem as atividades, como lareira, carpete, fogão, ar condicionado, aquecedor central etc.

Resta evidente que os cômodos e eletrodomésticos estão articulados a um tipo específico de casa, aquele da classe média ou média-alta de países anglófonos ricos, como o Reino Unidos e os Estados Unidos. A inexistência de pluralidade de representações de espaços e de identidades a eles vinculados aponta para o fato de que o English File não se articula aos pressupostos do ensino de ILI debatidos acima. Convém ressaltar ainda que não encontramos, na unidade analisada, a tentativa do 
desenvolvimento de atividades que pudessem levar à conscientização em relação à diversidade linguística que caracteriza o inglês na contemporaneidade.

\subsection{World English}

A coleção de livros World English, por sua vez, desde sua concepção, aparenta procurar se articular a um panorama mais geral de variantes e falantes de inglês. Em sua capa e contracapa, já temos a seguinte informação: "Pessoas de verdade. Lugares de verdade. Língua de verdade". De fato, percebe-se um maior cuidado na escolha de pessoas e de variantes orais de inglês que compõem o conjunto da edição. Temos usuários de inglês provenientes dos Estados Unidos, do Japão, do México, de Hong Kong e da Itália. Em relação à escrita, a grafia estadunidense está presente ao longo da unidade.

Além da escolha de falantes de diferentes variantes de inglês, convém também ressaltar a representação de questões culturais: temos, especialmente nas atividades de áudio, referências a questões climáticas de onde vivem, bem como de características de composição familiar. Dito isso, tal como visto no English File, a unidade do World English privilegia sobremaneira casas e habitações que são típicas de classes sociais mais ricas algo que pode ser observado nas Figuras 3 e 4, abaixo: 
Figuras 3 e 4: Atividades de vocabulário sobre moradias e cômodos.
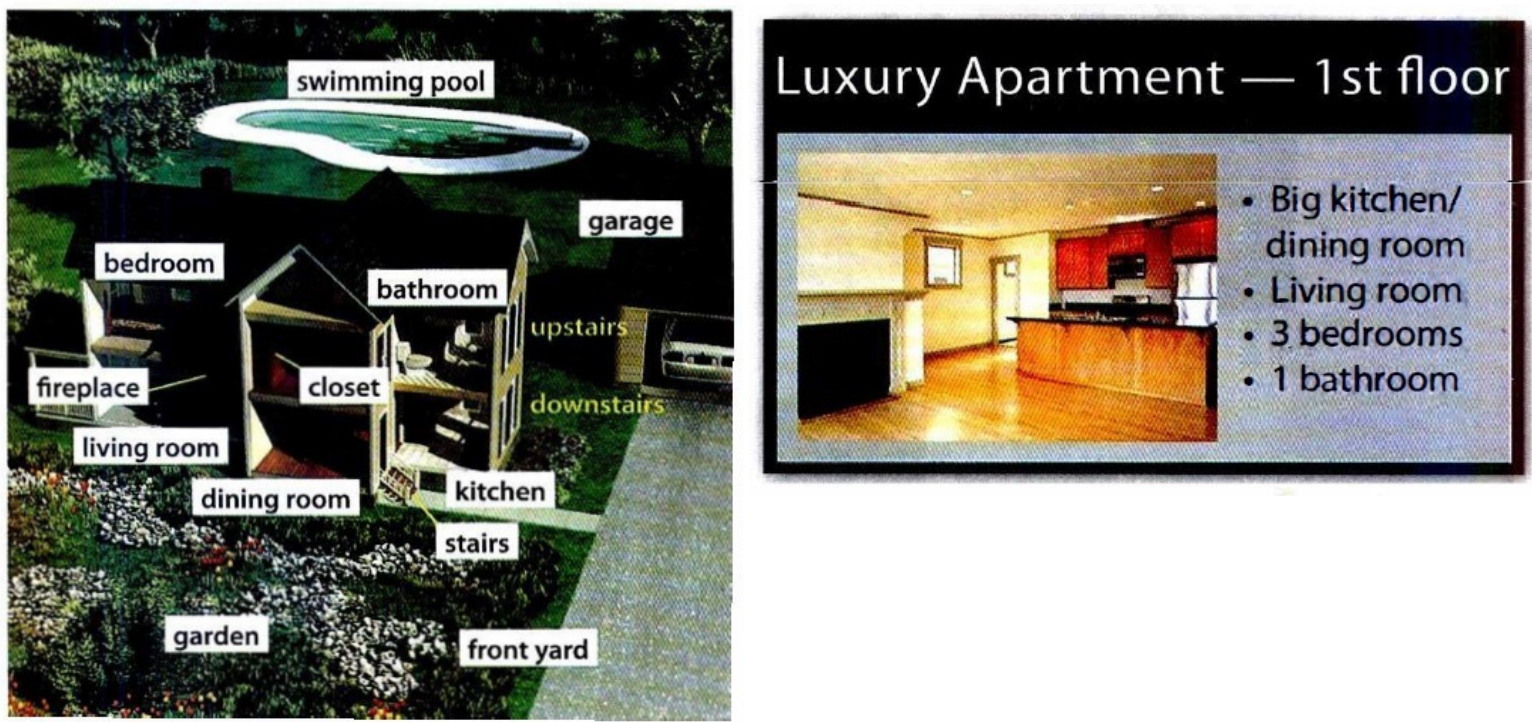

Fonte: MILNER, 2010, p. 28, 29.

Afora uma imagem de uma habitação africana (uma casa típica da savana, com telhado de palha), somente em uma seção de leitura, que traz um texto intitulado "Casas Incomuns" ["Unusual Houses"], temos representadas formas de viver em uma moradia que fogem ao padrão ocidental de classe média ou classe média-alta. Vejamos o texto da figura 5 . 
Figura 5: Texto intitulado "Unusual Houses".

\section{Unusual Houses}

The Kombai people of Irian Jaya live in tree houses. The houses are high in the trees. There is only one room in the house. It is the kitchen, the living room, the dining room, and the bedroom.

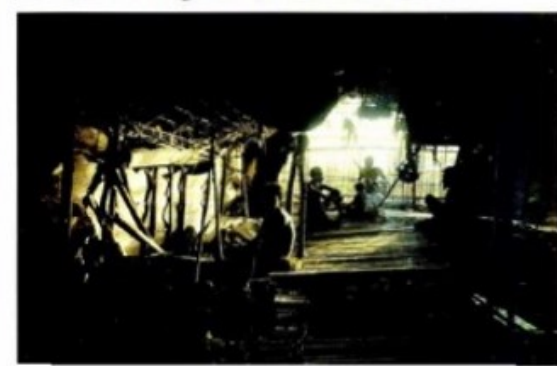

Abraham Niaqu is from Quebec in Canada. He is making a snow house called an igloo. There is only one room in an igloo. It is not cold in an igloo. In fact, it is quite hot.

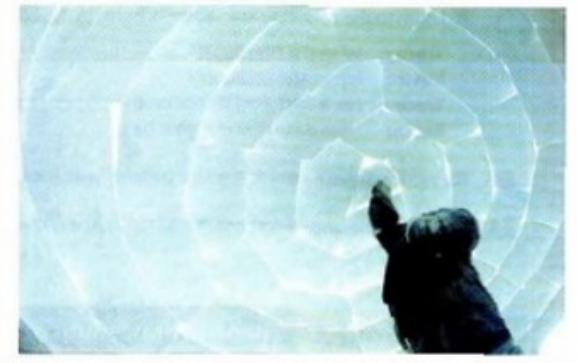

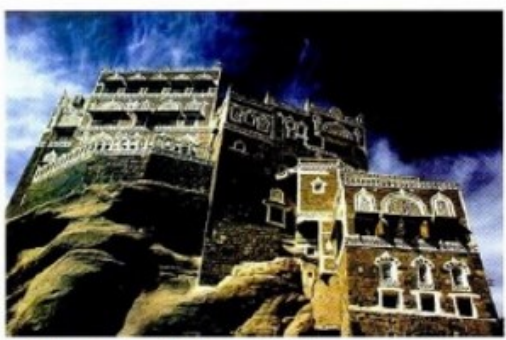

This house is called Dar Al Hajar. It is in Yemen. It is a big house and there are a lot of rooms in the house. It is hot in Yemen, but it is not hot inside the house.

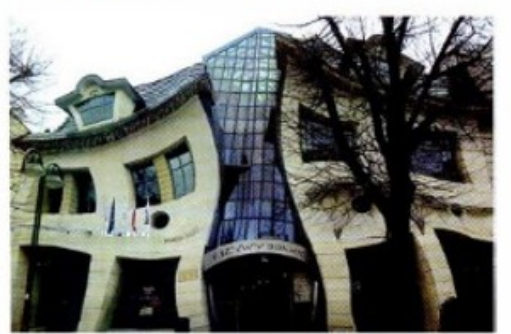

This house is called the Crooked House. However, it is not a house. Nobody lives in it. It is a shop-a very special shop! The architect, Szotynscy Zaleski, got the idea from a children's book. It is very unusual.

Fonte: MILNER, 2010, p. 34-35.

É bastante positiva a preocupação com a pluralidade de representações culturais e identitárias. Destacam-se, nesse sentido, a presença de um povo indígena da Indonésia, da casa típica do povo esquimó, o iglu, e de uma mansão no lêmen, Oriente Médio. O que é bastante preocupante, porém, é que tais residências e identidades a elas atreladas estão apontadas e circunscritas em articulação à característica do incomum, inclusive postas em paralelo com uma casa artística e curvilínea, realmente criada para ser incomum, como um desafio à arquitetura e à engenharia. Ora, devemos pensar, se é 
incomum, é porque há um comum - e o comum, pela leitura da unidade, é aquele representativo das classes mais ricas do mundo ocidental europeu e norte-americano.

Tem-se, pois, uma posição etnocêntrica em relação àquilo que é diferente da norma predominante na unidade analisada. Como afirmado anteriormente, isso pode ser bastante prejudicial no processo de ensino-aprendizagem, por potencialmente influenciar o desenvolvimento de percepções negativas sobre aquilo que pode ser visto como simplesmente diferente. $\mathrm{O}$ fato de que tais representações se encontram em um livro para ensino de inglês distribuído mundialmente também preocupa: não poderiam os próprios moradores das casas representadas, ou pessoas em situação habitacional semelhante, sentirem-se alienados ao estudarem por esse material didático, uma vez que são apontados como "incomuns"?

Por fim, convém chamar atenção para o fato de que também não foi possível encontrar nessa unidade analisada, para além da inserção de atividades com diferentes variantes orais de inglês, o desenvolvimento de atividades explícitas que buscassem a conscientização em relação à diversidade linguística que caracteriza o inglês na contemporaneidade. Somente uma análise mais aprofundada do livro didático como um todo, porém, permitiria a avaliação se o problema persiste ao longo do livro ou se tal material cometeu um deslize somente nessa unidade - levando a cabo mudanças cosméticas e superficiais, como argumenta Kumaravadivelu (2012), a fim de parecer mais articulado às discussões contemporâneas de ILI.

\subsection{Discussão/Sugestões}


Neste artigo, acompanhamos a maioria dos linguistas aplicados que se voltam para ILI, para quem os livros didáticos de ensino de língua inglesa precisam ser complementados com outros materiais didáticos, a fim de que se articulem de maneira mais próximas aos princípios da área, a exemplo de llieva (2018), Matsuda (2012) e Shin, Eslami e Chen (2011).

No contexto específico brasileiro, tal complementação às unidades analisadas seria essencial, visto que ambas não dialogam abertamente com questões próprias de moradias e identidades brasileiras. Para tanto, panfletos turísticos, jornais, revistas, mídias audiovisuais, relatórios da ONU etc, muitos deles amplamente disponíveis na internet, podem ser ferramentas úteis a fim de aproximar os livros didáticos da cultura e da realidade locais. De forma ideal, o professor de língua inglesa receberia formação reflexiva inicial e continuada, que possibilitem torná-lo não apenas consumidor ou implementador das ideias e propostas de outrem. Com as formações, ele seria capaz, pois de construir um olhar crítico ao material. E isso é especialmente importante quando consideramos a argumentação de Ilieva $(2018$, p. 11) de que, afinal, "ninguém está prevendo a morte dos livros didáticos no futuro próximo".

Por fim, além do material produzido pelas editoras e daqueles suplementares organizados pelos professores, Matsuda (2012) sugere que determinadas aulas podem ter como foco discussões que promovam a conscientização dos alunos acerca da diversidade linguística na contemporaneidade, através de uma exposição de conceitos e questões que marcam as próprias discussões nas áreas de LA e de ILI.

Ambas as unidades analisadas se encontram em livros que claramente passaram por um cuidadoso processo de composição e de edição. Não queremos, com esse texto, crucificar as editoras e os autores desses materiais - até porque, eles são excelentes em 
outros aspectos, como, por exemplo, o trabalho com as diversas linguagens semióticas: imagens, sons, vídeos, etc. Caso algum professor de inglês se encontre na iminência de precisar utilizar algum desses dois livros, acreditamos que uma filiação aos preceitos do ILI é possível, através da adaptação e complementação desses materiais.

\section{Considerações finais}

Neste artigo, desenvolvemos a análise de duas unidades de livros didáticos de acordo com os preceitos do ILI. Partimos do pressuposto de que o ensino do idioma a partir desses fundamentos configuram uma pedagogia sensível às questões sociais e aos diferentes usos que ocorrem com a língua inglesa na contemporaneidade globalizada.

Argumentamos que os livros didáticos são uma ferramenta essencial para a prática de um professor de ILI, uma vez que 1. nem todos os professores necessariamente possuem o conhecimento sobre muitas variantes de inglês e de seus falantes e 2 . livros didáticos têm um enorme potencial para formar, moldar e deformar opiniões e percepções de professores e alunos acerca das diferentes variantes de inglês faladas no mundo, bem como de seus diversos falantes.

Esperamos que as questões aqui apresentadas possam contribuir, em geral, com as discussões sobre ensino de língua inglesa em contexto nacional, e, mais específica e especialmente, com a prática de ensino do idioma de acordo com os fundamentos que guiam a área de ILI. 


\section{Referências}

ANDRADE, Eliane Righi de. Representações de idosos em livros didáticos de língua portuguesa para o ensino fundamental. In: CORACINI, Maria José e CARMAGNANI, Anna Maria G. (orgs.). Mídia, exclusão e ensino: dilemas e desafios na contemporaneidade. Campinas: Pontes Editora, 2014, p. 139-161.

ILIEVA, Roumiana. Textbooks. In: LIONTAS, John L. (ed.). The TESOL Encyclopedia of English language teaching, 2018. DOI: 10.1002/9781118784235.eelt0666.

KACHRU, Yamuna. Teaching and learning of World Englishes. In: HINKEL, Eli. (org.). Handbook of research in second language teaching and learning. New Jersey: Lawrence Erlbaum Associates, 2005.

KLEIMAN, Angela B. Agenda de pesquisa e ação em linguística aplicada: problematizações. In: MOITA LOPES, Luiz Paulo da. (org.). Linguística aplicada na modernidade recente: Festschrift para Antonieta Celani. São Paulo: Parábola Editorial, 2013, p. 39-58.

KUMARAVADIVELU, B. Individual identity, cultural globalization, and teaching English as an international language: the case for an epistemic break. In: ALSAGOFF, Lubna et al. (orgs.). Principles and practices for teaching English as an international language. New York and London: Routledge, 2012, p. 9-27.

LATHAM-KOENIG, Christina; OXENDEN, Clive; SELIGSON, Paul. English File: elementary student's book. 3. ed. Oxford: Oxford University Press, 2015.

MATSUDA, Aya. Teaching Materials in EIL. In: ALSAGOFF, Lubna et al. (orgs.). Principles and practices for teaching English as an international language. New York and London: Routledge, 2012, p. 168-185.

MCKAY, Sandra Lee. Principles of Teaching English as an International Language. In: ALSAGOFF, Lubna et al. (orgs.). Principles and practices for teaching English as an international language. New York and London: Routledge, 2012, p. 28-46.

MILNER, Martin. World English: intro student's book. Mason: Cengage Learning, 2010.

MOITA LOPES, Luiz Paulo da. Linguística aplicada e vida contemporânea: problematização dos construtos que têm orientado a pesquisa. In: . (org.). Por uma linguística

aplicada INdisciplinar. São Paulo: Parábola Editorial, 2006, p. 85-107. 
ROJO, Roxane. Pedagogia dos multiletramentos: diversidade cultural e de linguagens na escola. In: ; MOURA, Eduardo. (orgs.). Multiletramentos na escola. São Paulo:

Parábola Editorial, 2012, p. 11-31.

SHIN, Jeeyoung; ESLAMI, Zohreh R.; CHEN, Wen-Chun. Presentation of local and international culture in current international English-language teaching textbooks. Language, Culture and Curriculum, v. 24, n. 3, 2011, p. 253-268.

Recebido em 30 de agosto de 2019.

Aceite em 25 de novembro de 2019.

1 Essas e as demais traduções são de responsabilidade do autor do artigo. 